\title{
PENGAMAN PINTU RUMAH BERBASIS SENSOR SIDIK JARI DAN MAGNETIC SENSOR
}

\author{
Ade Septryanti ${ }^{1}$, Erlangga Satria Permana ${ }^{2}$ \\ ${ }^{12}$ Teknik Informatika/ Institut Sains Bisnis ATMA LUHUR \\ Jl. Jend. Sudirman kel.Selindung, kec.Gabek, Kota Pangkalpinang \\ 1adeseptryanti@atmaluhur.ac.id, ${ }^{2} 1211500017 @$ mahasiswa.atmaluhur.ac.id
}

\begin{abstract}
Abstrak- Rumah memiliki satu bagian yang penting yaitu pintu, dimana pintu merupakan akses utama bagi penghuni rumah. Pintu mempunyai kunci ketika ingin membukanya, untuk membuka sebuah pintu terkadang kunci rumah rentan akan patah, duplikasi atau pun hilang. Pemakaian sensor sidik jari pada pintu dapat membantu pemilik rumah agar tidak terjadi pencurian yang dimana ketika tidak sesuai dengan identitas penghuni rumah maka SIM 900 GSM akan mengirimkan sms notifikasi dan buzzer sebagai alarm akan berbunyi. Model Prototype meliputi tahapan pengumpulan kebutuhan, membangun prototype, evaluasi, pengkodean sistem, menguji sistem, evaluasi sistem dan penggunaan sistem. Alat sensor sidik jari tersebut sudah diuji dan dapat digunakan pada penghuni rumah untuk mendukung keamanan pada pintu.
\end{abstract}

Kata Kunci- sensor sidik jari , pintu, SIM 900 GSM

Abstract-The house has one important part, the door, where the door is the main access to the occupants of the house. The door has a key when wanting to open it, to open a door sometimes the house key is vulnerable to being broken, duplicated or even lost. The use of fingerprint sensors on the door can help homeowners avoid theft, which is when it is not in accordance with the identity of the residents of the GSM 900 SIM will send an SMS notification and a buzzer as an alarm will sound. Prototype models include the stages of gathering needs, building prototypes, evaluating, coding the system, testing the system, evaluating the system and using the system. Fingerprint sensor has been tested and can be used on residents to support security at the door.

Keywords - finger print sensor, door, SIM 900 GSM

\section{PENDAHULUAN}

Tingkat bahaya bisa terjadi kapan saja dan dimana saja disaat sedang berada didalam atau diluar rumah. Bahaya tersebut bisa terjadi berupa kebanjiran, pencurian, kebakaran dan sebagainya, oleh karena itu pemilik rumah harus tetap waspada agar tidak terjadi yang tidak inginkan. Tingkat keamanan rumah sangat diperhatikan, rumah merupakan tempat yang nyaman dan untuk melindungi penghuni dari segala ancaman yang datang. Penghuni rumah bisa memasang alat pengamanan pada pintu agar tidak terjadinya pencurian. Ada dua alasan kenapa rumah bisa terjadi pencurian antara lain lampu pada rumah ketika malam hari tidak dihidupkan, menitipkan kunci rumah kepada orang yang kurang dipercayai. Pengamanan pada rumah begitu penting terutama pada bagian pintu, dimana untuk membuka pintu menggunakan kunci dan pintu merupakan jalan utama masuknya pencuri ke rumah. Pengunaan kunci pada pintu rumah sering terjadi kehilangan sehingga pintu rumah tidak bisa dibuka. Pengamanan pintu yang sering di jumpai yaitu CCTV, teralis, dan sensor sidik jari. Pada saat ini pengunaan sidik jari dengan mengenali pola pada jari belum banyak diterapkan, dimana penggunaan sidik jari ini pada sebuah pengamanan pintu memiliki tingkat keamanan yang sangat tinggi dan mudah digunakan. Penggunaan sidik jari bukan hanya untuk dirumah saja tapi pada perkantoran dan rumah sakit. Pada penelitian[1] menjelaskan bahwa untuk membuat akses kontrol ruangan menggunakan sensor sidik jari berbasis mikrokontroler ATmega 328p dimana pada hasilnya sensor sidik jari dan sensor gerak dapat berfungsi untuk membuka pintu dan menutup pintu.

\section{TINJAUAN PUSTAKA}

\section{A. Mikrokontroler}

Mikrokontroler[2] adalah sistem mikroprosesor lengkap yang terkandung di dalam sebuah chip. Mikrokontroler berbeda dari mikroprosesor serbaguna yang digunakan dalam sebuah PC, karena sebuah mikrokontroler umumnya telah berisi komponen pendukung sistem minimal mikroprosesor, yakni memori dan pemrograman Input-Output. Mikrokontroler dapat diprogram untuk melakukan penghitungan, menerima input dan menghasilkan output. Mikrokontroler mengandung sebuah inti processor, memori dan pemrograman Input-Output. [3]Fungsi mikrokontroler ini adalah untuk membaca dan menulis data yang bertujuan untuk 
mengefisienkan pekerjaan dan mengurangi pembiayaan yang diperlukan.

\section{B. Arduino}

Arduino adalah kit elektronik atau papan Page|306 rangkaian elektronik open source yang didalamnya terdapat komponen utama yaitu sebuah chip mikrokontroler dengan jenis AVR. Mikrokontroler itu sendiri adalah chip atau IC (Integrated Circuit) yang bisa diprogram menggunakan komputer. Tujuan menanamkan program pada mikrokontroler adalah agar rangkaian elektronik dapat membaca input, proses dan output sebuah rangkaian elektronik[4]. Kelebihan Arduino diantaranya adalah tidak perlu perangkat chip programmer karena di dalamnya sudah ada bootloader yang akan menangani upload program dari komputer, Arduino sudah memiliki sarana komunikasi USB, sehingga pengguna laptop yang tidak memiliki port serial/RS323 bisa menggunakannya [5].

\section{Arduino Uno}

Arduino UNO[84-277-1-PB] adalah sebuah board mikrokontroler yang didasarkan pada ATmega328 (datasheet). Arduino UNO memiliki 14 pin digital input/output (dimana 6 pin dapat digunakan sebagai output PWM), 6 input analog, clock speed $16 \mathrm{MHz}$ koneksi USB, jack listrik, header ICSP, dan tombol reset. Board ini menggunakan daya yang terhubung ke komputer dengan kabel USB atau daya external dengan adaptor AC-DC atau baterai. [106155-348911-PB]Arduino UNO memuat semua yang dibutuhkan untuk menunjang mikrokontroler, mudah menghubungkannya ke sebuah komputer dengan sebuah kabel USB atau mensuplainya dengan sebuah adaptor AC ke DC atau menggunakan baterai untuk memulainya. Kelebihan arduino diantaranya adalah tidak perlu perangkat chip programmer karena di dalamnya sudah ada bootloader yang akan menangani upload program dari komputer.

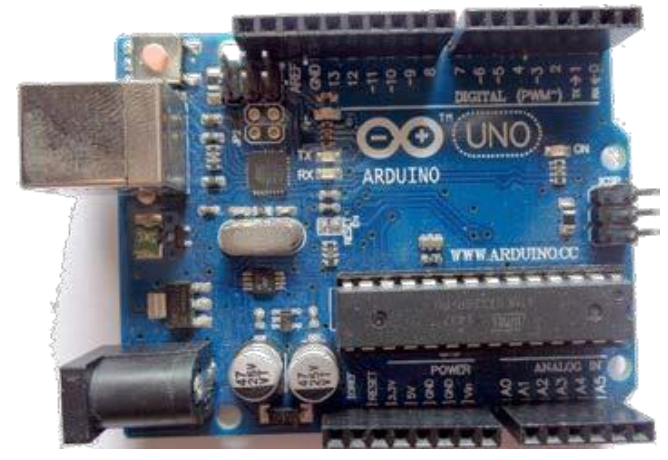

Gbr 1. Bentuk Fisik Board Arduino Uno

\section{Sensor Sidik Jari}

Sensor sidik jari (fingerprint) merupakan alat yang dapat membaca pola guratan - guratan pada kulit tangan manusia. Sistem biometrik ini banyak digunakan karena memiliki keakurasian yang tinggi, mudah dimanfaatkan dan masing-masing individu berbeda - beda, sehingga aplikasi untuk sekuritas atau akses kontrol sangat tepat digunakan[sentika 14]. Salah satu jenis sensor fingerprint adalah Fingerprint ZFM-20, modul fingerprint inilah yang digunakan dalam penelitian ini. Modul sensor[4] ini dilengkapi dengan DSP (Digital Signal Processing) yang melakukan image rendering kemudian mengkalkulasi, feature-finding dan terakhir searching pada data yang sudah ada [document (1)].

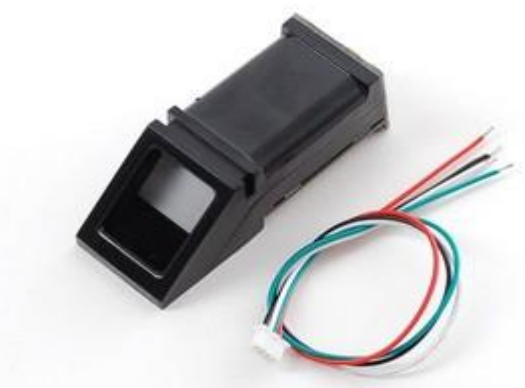

Gbr 2. Bentuk Fisik Sensor Sidik Jari

\section{E. Magnetic Sensor}

Magnetic Sensor atau Sensor Magnet yang biasa disebut juga sensor pintu, adalah alat yang akan terpengaruh medan magnet dan akan memberikan perubahan kondisi pada keluaran. Seperti layaknya saklar dua kondisi (on/off) yang digerakkan oleh adanya medan magnet di sekitarnya. Biasanya sensor ini dikemas dalam bentuk kemasan yang hampa dan bebas dari debu, kelembapan, asap ataupun uap[3].

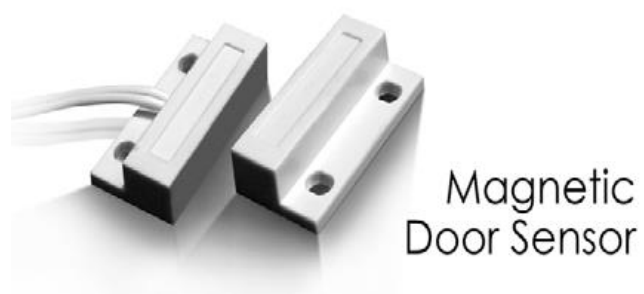

Gbr 3. Bentuk Fisik Magnetic Sensor

\section{F. Solenoid DoorLock}

Solenoid DoorLock merupakan salah satu solenoid yang difungsikan khusus sebagai solenoid untuk pengunci pintu secara elektronik. Solenoid ini mempunyai dua sistem kerja, yaitu Normaly Close $(N C)$ dan Normaly Open (NO). Perbedaan dari keduanya adalah jika cara kerja solenoid NC apabila diberi tegangan, maka solenoid akan memanjang (tertutup) dan untuk cara kerja dari Solenoid NO adalah kebalikannya dari Solenoid NC [164-308-1$\mathrm{SM}$. (tertutup) dan untuk cara kerja dari Solenoid NO adalah kebalikannya dari Solenoid NC [3]. 


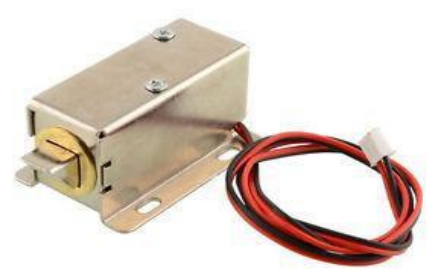

Gbr 4. Bentuk Fisik Selenoid DoorLock

\section{G. SIM900 GSM/ GPRS}

SIM900 GSM/GPRS adalah bagian yang berfungsi untuk berkomunikasi antara pemantau utama dengan Handphone. ATCommand adalah perintah yang dapat diberikan modem GSM/CDMA seperti untuk mengirim dan menerima data berbasis GSM/GPRS, atau mengirim dan menerima SMS. SIM900 GSM/GPRS dikendalikan melalui perintah AT (GSM 07.07, 07.05, dan SIMCOM)[7].

Spesifikasi Modul SIM900A adalah sebagai berikut:

1. Frekuensi kerja: $900 \mathrm{MHz} / 1800 \mathrm{MHz}$

2. Bekerja pada tegangan: $4,4 \sim 5,3 \mathrm{VDC}$

3. Arus yang digunakan: maksimum $2 \mathrm{~A}$, rata-rata $50 \mathrm{~mA}$

4. Arus Mode Sleep: 4mA

5. Komunikasi Interface: port serial TTL

6. Tegangan Antarmuka: 3.3V

7. Membuat dan menjawab panggilan telepon menggunakan headset atau speaker 8 ohm eksternal

dan mikrofon electret.

8. Mengirim dan menerima pesan SMS.

9. Mengirim dan menerima data GPRS (TCP / IP, HTTP, dll).

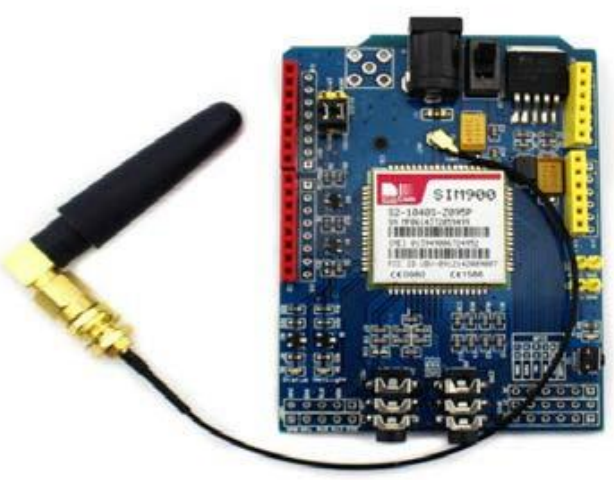

Gbr 5.Bentuk Fisik SIM900 GSM

\section{H. LCD (LIQUID CRYSTAL DISPLAY)}

LCD (Liquid Crystal Display) merupakan perangkat elektronik yang dapat digunakan untuk menampilkan angka atau teks. Ada dua jenis utama layar LCD yang dapat menampilkan numerik (digunakan dalam jam tangan, kalkulator) dan menampilkan teks alfanumerik (sering digunakan pada mesin foto kopi dan telepon genggam)[8].

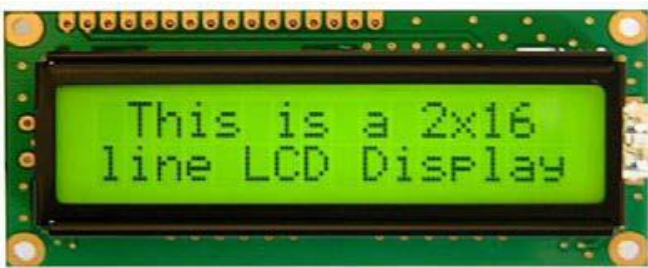

Gbr 6. Bentuk fisik LCD

\section{METODOLOGI PENELITIAN}

\section{A. Model Prototype}

Model Prototype [10.1.1.843.2205] merupakan metode pengembangan perangat lunak, yang berupa model fisik kerja sistem dan berfungsi sebagai versi awal dari sistem. Prototype akan dihilangkan atau ditambahkan pada bagiannya sehingga sesuai dengan perencanaan dan analisis yang dilakukan oleh pengembang sampai dengan ujicoba dilakukan secara simultan seiiring dengan proses pengembangan. Ada 4 metodologi prototyping yang paling utama yaitu :

1. Illustrative, menghasilkan contoh laporan dan tampilan layar.

2. Simulated, mensimulasikan beberapa alur kerja sistem tetapi tidak menggunakan data real.

3. Functional, mensimulasikan beberapa alaur sistem yang sebenarnya dan menggunakan data real.

4. Evolutionary, menghasilkan model yang menjadi bagian dari operasional sistem.

Prototyping bagi pengembang sistem bertujuan untuk mengumpulkan informasi dari pengguna sehingga pengguna dapat berinteraksi dengan model prototype yang dikembangkan, sebab prototype menggambarkan versi awal dari sistem untuk kelanjutan sistem sesungguhnya yang lebih besar[10.1.1.675.391]. [10.1.1.843.2205]Telah ditemukan bahwa dalam analisis dan desain sistem, terutama untuk proses transaksi, di mana dialog yang ditampilkan lebih mudah difahami. Semakin besar interaksi antara komputer dan pengguna, besar pula manfaat yang diperoleh ketika proses pengembangan sistem informasi akan lebih cepat dan membuat pengguna akan lebih interaktif dalam proses pengembangannya. Manfaat lainnya dari penggunaan prototyping adalah :

1. Mewujudkan sistem sesungguhnya dalam sebuah replika sistem yang akan berjalan, menampung masukan dari pengguna untuk kesempurnaan sistem.

2. Pengguna akan lebih siap menerima setiap perubahan sistem yang berkembang sesuai dengan berjalannya prototype sampai dengan hasil akhir pengembangan yang akan berjalan nantinya. 
3. Prototype dapat ditambah maupun dikurangi sesuai berjalannya proses pengembangan. Kemajuan tahap demi tahap dapat diikuti langsung oleh pengguna.

4. Penghematan sumberdaya dan waktu dalam menghasilkan produk yang lebih baik dan tepat guna bagi pengguna.

Sketsa awal atau prototype pertama dikembangkan untuk menentukan kebutuhan dari user [10.1.1.843.2205]

\section{IV.HASIL DAN PEMBAHASAN}

\section{A. Analisis Sistem Lama}

Analisis sistem lama yang digunakan sebelumnya dimana user ketika ingin membuka pintu menggunakan kunci yang sehingga sering terjadi kehilangan dan patah. Penggunaan kunci rentan sekali akan adanya penduplikasi kunci sehingga pemilik rumah tidak bisa melakukan pengecekan ketika penghuni rumah sedang tidak berada di rumah. Penggunaan kunci rumah yang di ganti dengan sensor sidik jari (fingerprint) sangat mudah untuk diimplementasikan. Berikut use case diagram dan activity diagram sistem lama yang selama ini di gunakan pada gambar di bawah ini :

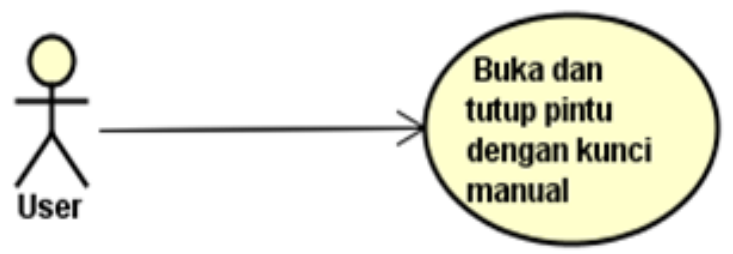

Gbr 7. Use Case Diagram Analisis Sistem Lama

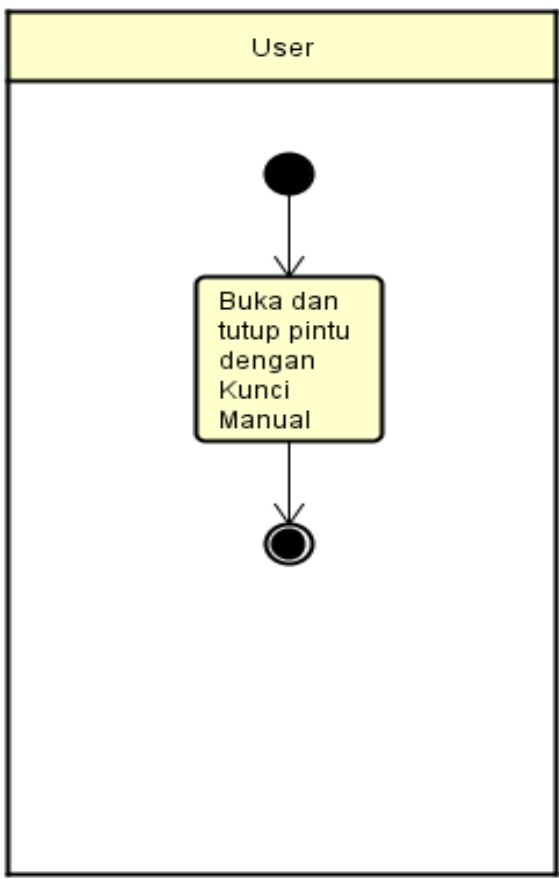

Gbr 8. Activity Diagram Analisis Sistem Lama

\section{B. Rancangan Proses Sistem Baru}

Pembuatan aplikasi pengamanan pintu berbasis sidik jari dan magnetic sensor dimana pemilik rumah menempelkan jarinya tersebut ke alat sensor sidik jari. Sidik Jari tersebut digunakan sebagai identitas pemilik rumah ketika ingin membuka pintu. Penentuan sidik jari yang benar atau tidak yang ditempelkan pada sensor dimana pemilik rumah bisa melihat dari LCD dan SIM 900 GSM mengirimkan notifikasi sms keamanan. Magnetic sensor yang digunakan agar pintu tidak bisa dibuka paksa dan buzzer akan mengeluarkan suara berupa peringatan kepada pemilik rumah bahwa pintu tersebut dibuka dengan paksa. Relay sebagai alat yang akan mengontrol langsung selenoid yang digunakan untuk membuka atau menutup kunci. Berikut di bawah ini gambar use case diagram dan activity diagram rancangan proses sistem baru :

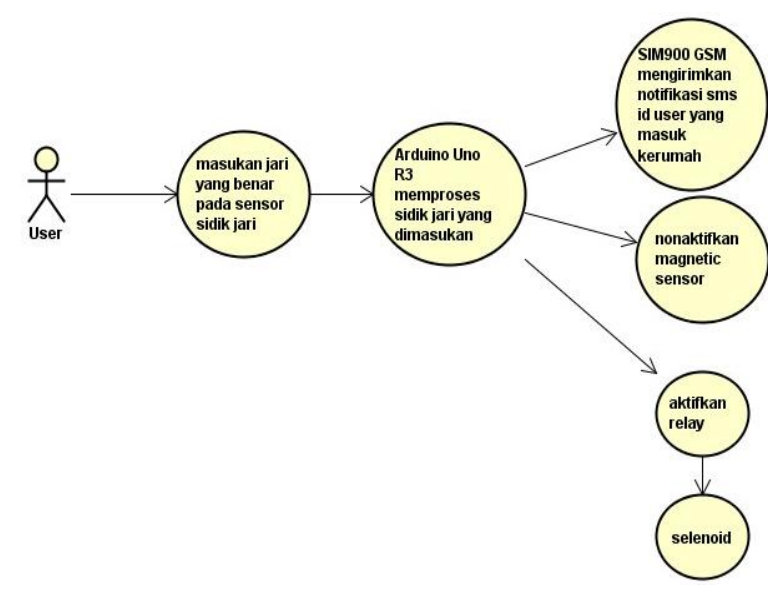

Gbr 9. Usecase Diagram Rancangan Proses Sistem Baru

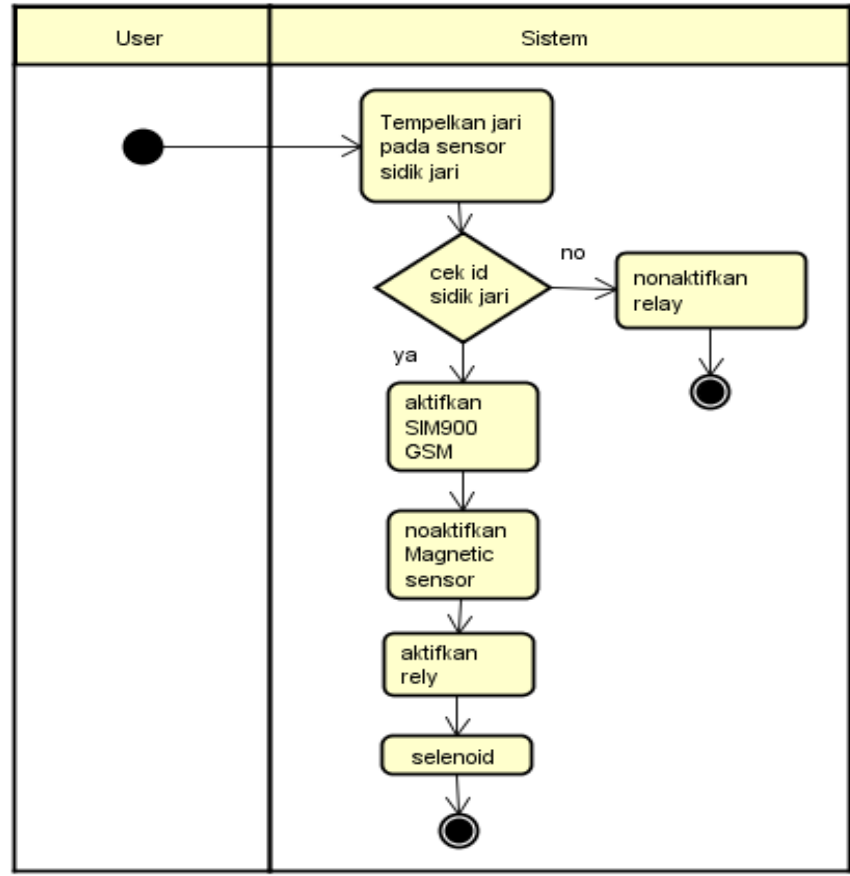

Gbr 10. Activity Diagram Rancangan Proses Sistem Baru 


\section{Rancangan Sistem Kerja}

Rancangan sistem kerja menjelaskan cara kerja sistem dan komponen alat yang dibuat dan digambarkan dalam sebuah deployment diagram. Deployment diagram digunakan untuk memahami

Page | 309 rancangan sistem kerja yang akan diterapkan. Berikut Deployment Diagram rancangan sistem kerja pada aplikasi pengamanan pintu rumah berbasis sidik jari dan magnetic sensor:

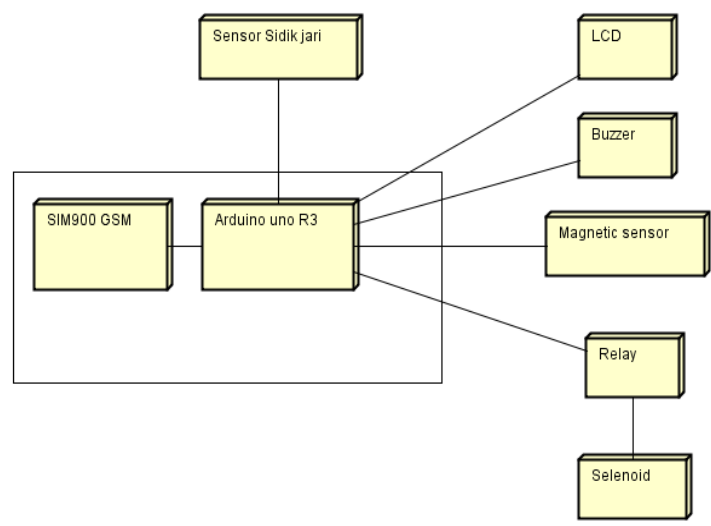

Gbr 11. Deployment Diagram Rancangan Sistem Kerja

\section{Rancangan Rangkaian Sensor Sidik Jari}

Rancangan Rangkaian Sensor Sidik Jari digunakan untuk memasukkan identitas pemilik rumah yang dibaca oleh mikrokontroler dan akan dibandingkan dengan data yang telah tersimpan pada memori. Jika sidik jari pemilik rumah benar maka SIM 900 GSM akan mengirimkan sms notifikasi kepada pemilik rumah siapa yang masuk kerumah. Berikut component diagram rancangan rangkaian sensor sidik jari :

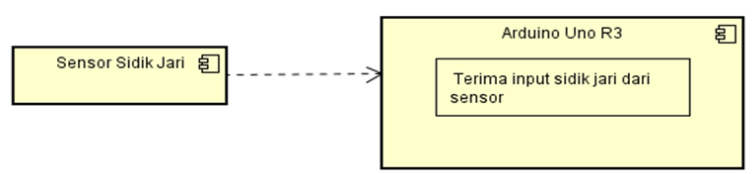

Gbr 12. Component Diagram Rancangan Rangkaian Sensor Sidik Jari

\section{E. Rancangan Rangkaian Magnetic Sensor}

Rancangan rangkaian magnetic sensor yang digunakan sebagai keamanan pada pintu yang di buka secara paksa tanpa memasukkan identitas berupa sidik jari pada alat tersebut. Berikut component diagram perancangan rangkaian magnetic sensor :

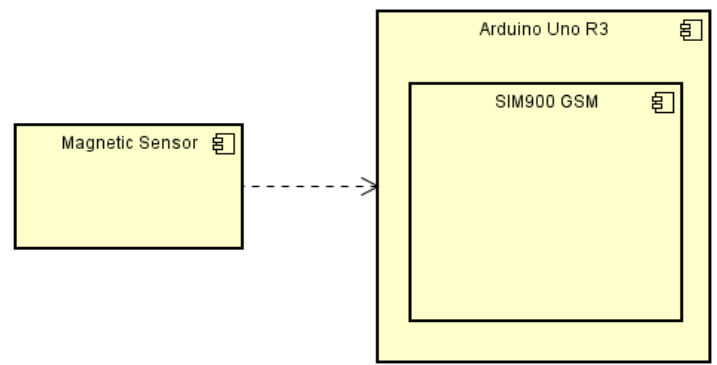

Gbr 13. Component Diagram Rancangan Rangkaian Magnetic Sensor

\section{F. Perancangan Rangkaian Keseluruhan}

Perancangan rangkaian keseluruhan merupakan rancangan keseluruhan yang terhubung dengan mikrokontroler yang terdiri dari sensor sidik jari, magnetic sensor ,buzzer,lcd, relay dan solenoid dan SIM 900 GSM. Berikut component diagram perancangan rangkaian keseluruhan :

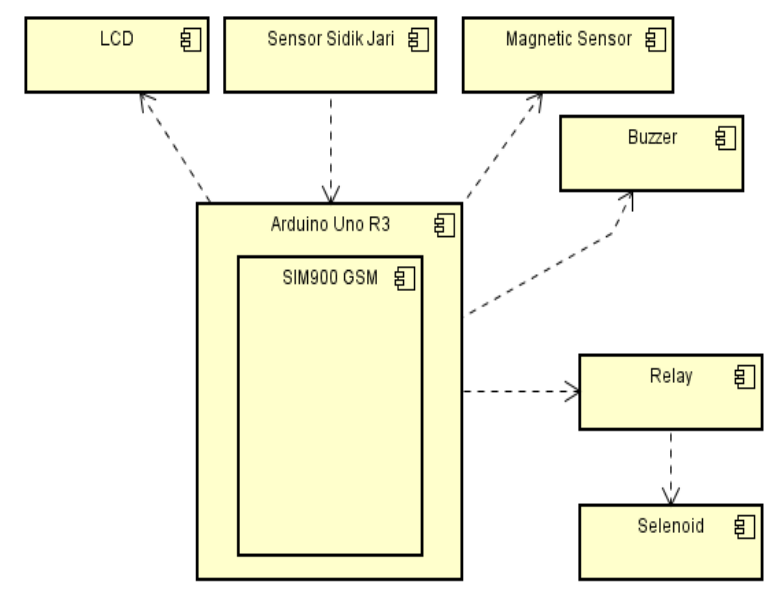

Gbr 14. Component Diagram Perancangan Rangkaian Keseluruhan

\section{G. Flowchart}

flowchart aplikasi pengaman pintu rumah berbasis sidik jari dan magnetic sensor, dimulai dari pembacaan sidik jari kemudian Arduino Uno R3 memproses sidik jari yang dimasukkan dan memberi perintah ke SIM900 GSM untuk mengirimkan notifikasi pesan serta non aktifkan magnetic sensor lalu diteruskan ke relay untuk mengaktifkan selenoid. Berikut flowchart aplikasi pengaman pintu rumah berbasis sidik jari dan magnetic sensor : 


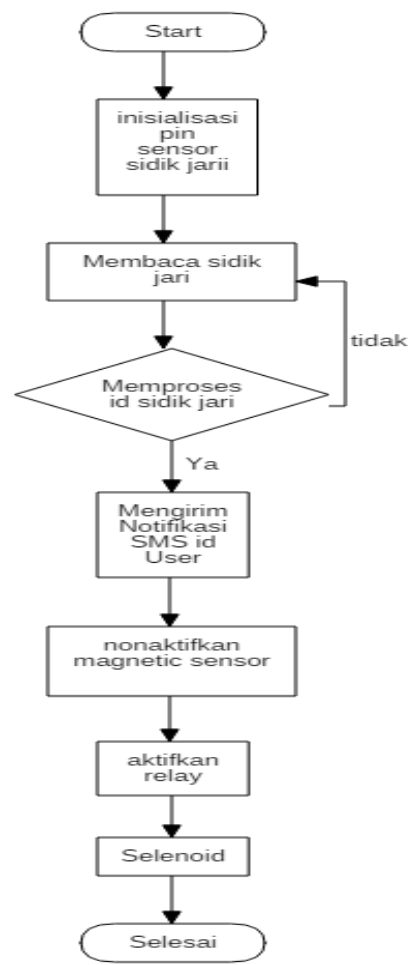

Gbr 15. flowchart aplikasi pengaman pintu rumah berbasis sidik jari dan magnetic sensor

H. Algoritma Rancang Bangun Aplikasi Pengaman Pintu Rumah Berbasis Sidik Jari dan Magnetic Sensor

INISIALISASI PIN
THEN
MEMBACA SIDIK JARI
MEMPROSES SIDIK JARI
IF NO
MEMBACA SIDIK JARI
IF YES
MENGIRIMKAN NOTIFIKASI SMS ID USER
THEN
NONAKTIFAN MAGNETIC SENSOR
AKTIFKAN
RELAY
SOLENOID
END

\section{Implementasi}

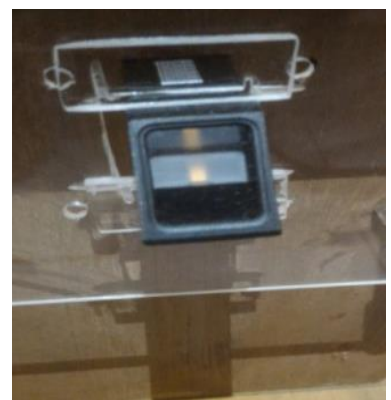

Gbr 16. Tampilan Rangkaian Sensor Sidik Jari

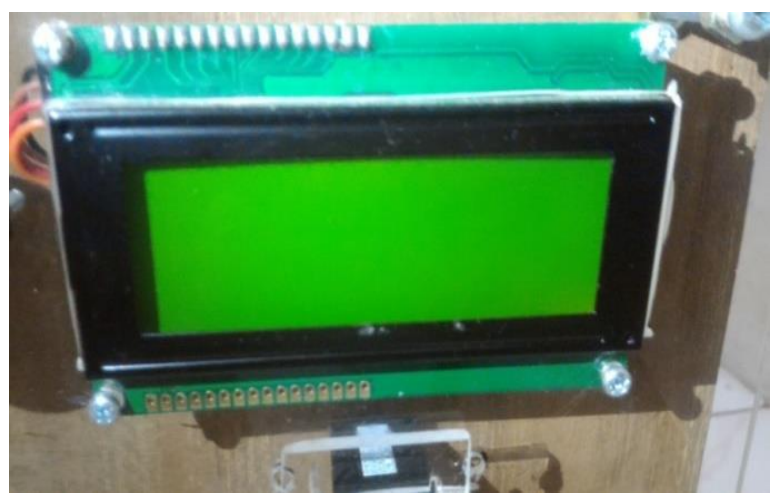

Gbr 17. Tampilan Rangkaian LCD

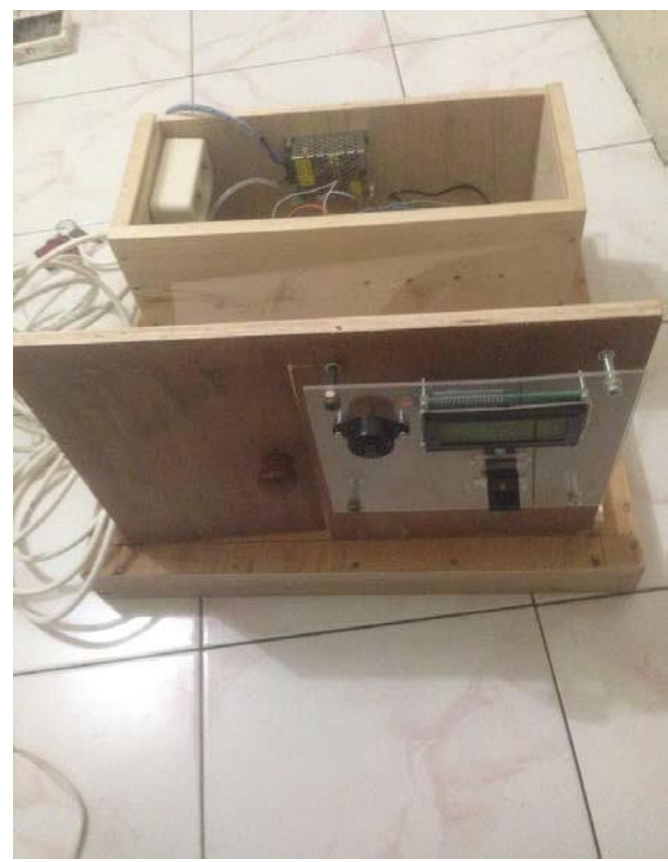

Gbr 18. Tampilan Rangkaian Keseluruhan

\section{PENUTUP}

Hasil penelitian penggunaan sidik jari pada pintu membuat pemilik rumah tidak akan takut untuk meninggalkan rumah dan ketika sensor sidik jari tersebut tidak sesuai dengan identitas pemilik maka SIM 900 GSM akan mengirimkan sms berupa pesan bahwa pintu rumah dibuka secara paksa dan alarm akan berbunyi yang dimana relay berfungsi sebagai sakelar yang menghubungkan solenoid dengan buzzer untuk membunyikan alarm.

\section{REFERENSI}

[1] D. Saputra et al., "Akses Kontrol Ruangan Menggunakan Sensor Sidik Jari,” vol. 2014, no. Sentika, 2014.

[2] I. Oktariawan, M. Sugiyanto, and J. Fema, "Pembuatan Sistem Otomasi Dispenser Menggunakan Mikrokontroler Arduino Mega 2560," vol. 1, no. April, pp. 18-24, 2013.

[3] D. I. Balai and D. Sukorejo, "Ruangan Menggunakan Rfid Pada E-Ktp," pp. 45-55.

[4] A. A. Rahmansyah and N. F. Apriadi, "Rancang Bangun Pagar Otomatis dengan Finger print Berbasis Mikrokontroller," vol. 3, pp. 35-40, 2017. 
[5] P. Studi and P. Teknik, "Rancang Bangun Magnetic Door Lock Menggunakan Keypad Dan Solenoid Berbasis Mikrokontroler Arduino Uno," vol. 12, no. 1, pp. 39-48, 2013.

[6] A. Fatoni, D. B. Rendra, P. Studi, S. Komputer, and I. Pendahuluan, "Perancangan Prototype Sistem Kendali Lampu Menggunakan Handphone Android," vol. 1, no. September, 2014.

Page | 311 [7] D. Y. Sukma, E. Safrianti, and C. Idrus, "Teknologi Informasi Dan Otomatisasi Tangki Minyak Berbasis Arduino Uno," pp. 101-106, 2019.

[8] S. Pemantauan et al., "1 2 1,2," pp. 1-7.

[9] P. Sharma and D. Singh, "Comparative Study of Various SDLC Models on Different Parameters," pp. 1-5, 2015.

[10] P. M. Ogedebe and B. P. Jacob, "Software Prototyping: A Strategy to Use When User Lacks Data Processing Experience," vol. 2, no. 6, pp. 219-224, 2012. 